
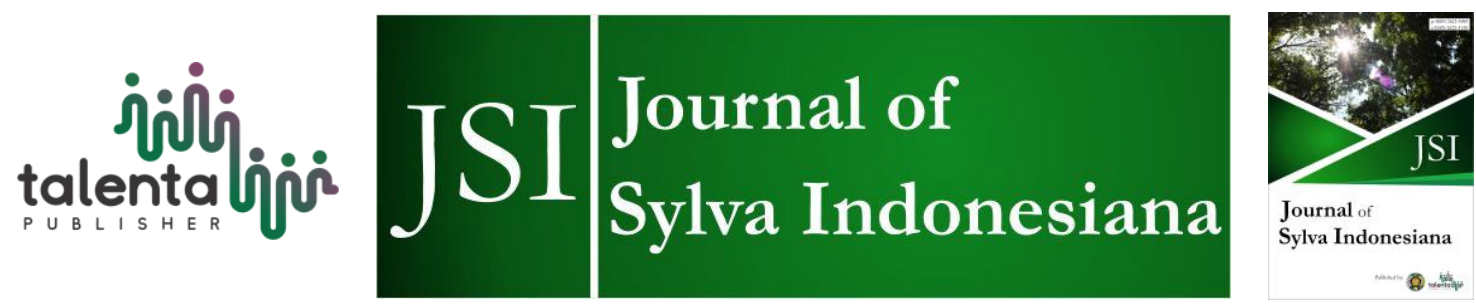

\title{
The Influence of Wood Species and Type of Strands Arrangement to The Physical and Mechanical Properties of Oriented Strands Board
}

\author{
Arif Nuryawan', Muh.Yusram Massijaya ${ }^{2}$, and Yusuf Sudo Hadi ${ }^{3}$ \\ ${ }^{I}$ Department of Forest Products Technology, Faculty of Forestry, Universitas Sumatera Utara, Medan, \\ Indonesia \\ ${ }^{2,3}$ Department of Forest Products, Faculty of Forestry, Bogor Agricultural University, Bogor, Indonesia,
}

\begin{abstract}
This research was concerning in mat forming method for production of oriented strands board (OSB) in laboratory scale. There were three prototype models of OSB resulted in method applied, namely manually alignment's model, using former device tool adopted from Nishimura's model, and using former device made of plywood and wire's model. From the physical and mechanical properties evaluation, the best mat of OSB was resulted in the third model, using former device made of plywood and wire.
\end{abstract}

Keyword: Alignment, Mat Forming, OSB, Physical and Mechanical Properties.

Received 18 Nopember 2017 | Revised 3 March 2018 | Accepted 18 May 2018

\section{Introduction}

The direction arrangement of strands mat is the most important process in the production of oriented strands board (OSB) to determine the quality of the board products. The strand board is consisted of two parts which are two parallel surfaces along the lengthwise direction and the main layer where the strands direction is perpendicular to the lengthwise or parallel to the widthwise direction of the panels [1].

There are two types of strands arrangement on the panels; they are mechanical orientation and electrical orientation. Mechanical orientation can be done by dropping the stands between parallel thin mats or by bringing them into narrow pockets for later dropping on the panels [2]. In electrical orientation, a strand is dropped between electrically charged plats, and because of the polar and electrically charged plat, it can be self-oriented $[3,4]$.

\footnotetext{
*Corresponding author at: Universitas Sumatera Utara, Padang Bulan, Medan, 20155, Indonesia E-mail address: arif5@usu.ac.id
} 
This orientation of strands direction may become a key factor in the strands board manufacture because it will determine the quality of the panels. Three models of strand panels based on the orientation of strands direction was made which were the panels with totally random strands direction, the direction of the strands was in to the main mat, and the direction of main mat was perpendicular to the direction of surface mat. The results showed that the strands direction into the surface and the main mats affects the value of the modulus of rupture and modulus of elasticity but does not affect the moisture content, thickness swelling, and internal bonding strength [5]. This research objective is to evaluate the influence of strands direction to the physical and mechanical characteristic of strands panels.

\section{Materials and Methods}

The materials were consisted of wood strands of acacia, eucalyptus, and gmelina with 8 to $9 \%$ of moisture content, phenol formaldehyde (PF) powder with solid resin $98.28 \%$ as an adhesive, and powder paraffin wax. Strands panel was made of three mats, surface and back mats were perpendicular to the middle mat.

The three strands orientation techniques in mat panel that have been done were: (1) strands manually arranged following bricks arrangement in the construction of buildings [5-9]; (2) strands were arranged using orientation tool that was made from adopted mat in Nishimura et al. in [2] as shown in Figure 1; (3) strands was constructed using an orientation tool that was modified from the Nishimura et al. in [2] by replacing the mat with a wire as shown in Figure 2.

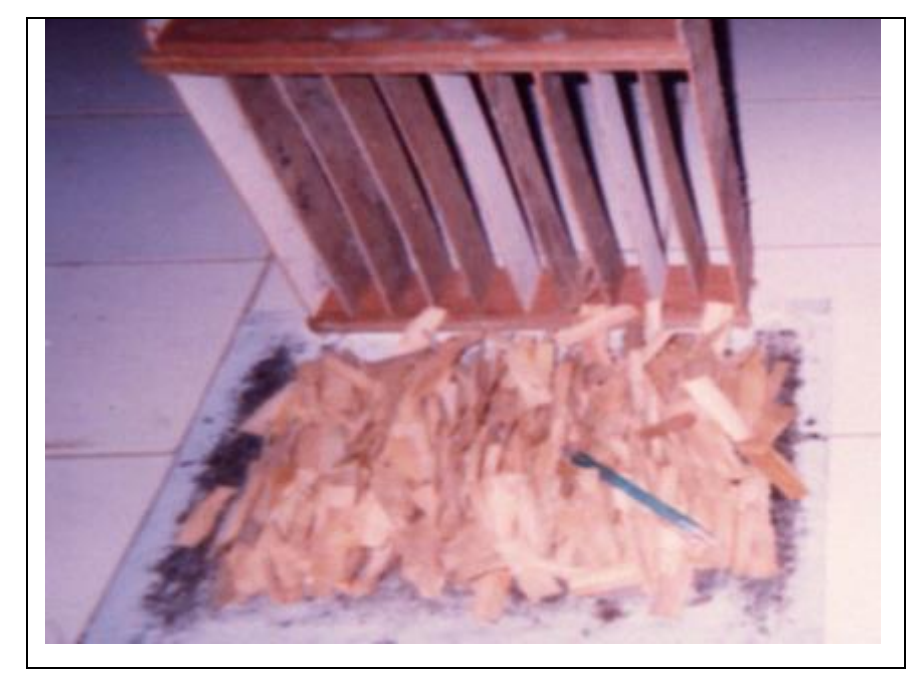

Figure 1 Strands orientation tool in the strands making adopted from Nishimura et al. cited in [2].

Strand panels were made by length, width, and thickness $30 \mathrm{~cm}$ by $30 \mathrm{~cm}$ by $0.9 \mathrm{~cm}$ following below procedure: 
1. The panel target density was $0.75 \mathrm{~g} / \mathrm{cm}^{3}$ with two replications and resulted in 18 strand mats.

2. Paraffin powder (1\% of strands dried weight) and PF powder (5\% of strands dried weight) were mixed with the strands before their orientation was arranged in the mold.

3. The hot pressing was carried out using a specific pressure of $25 \mathrm{~kg} / \mathrm{cm}^{2}$ or a pressure meter of $90 \mathrm{~kg} / \mathrm{cm} 2$ and at temperature $160^{\circ} \mathrm{C}$ with total pressing time 15 minutes with 5 minutes for control position until it reached $20 \mathrm{~mm}$ thickness and 10 minutes was needed to maintain at a thickness of $9 \mathrm{~mm}$.

4. Strand panels were conditioned to keep at room temperature for two weeks before they were physically and mechanically analyzed based on Japanese Industrial Standard (JIS) A $59082003[1]$.

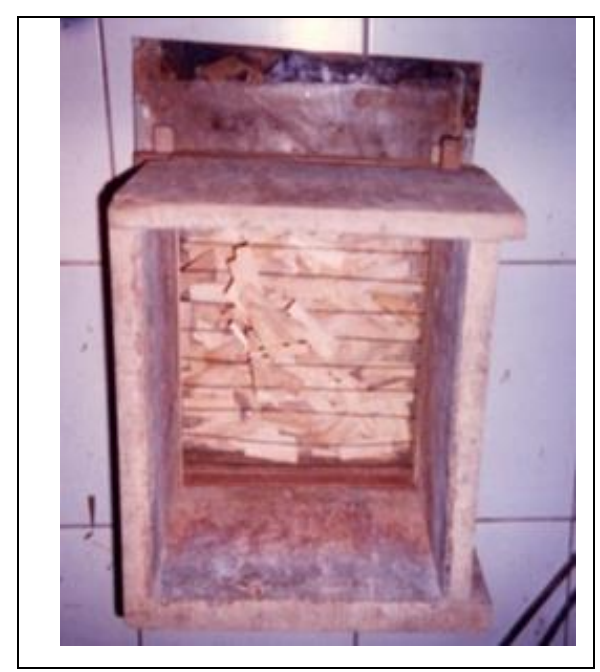

Figure 2 The improved strands orientation tool adopted from Nishimura et al. cited in [2].

The best strand panel was the one that had the best performance after physically and mechanically analyzed. Then, the produced strand panels were arranged based on their analysis scores from the highest to the lowest scores, with the highest score as the best panel.

The quality parameters of panels for physical analysis were panel density, moisture content, thickness swelling, and water absorption ability while the mechanical parameters for analysis consisted of internal bonding, modulus of rupture, and modulus of elasticity.

\section{Result and Discussion}

\subsection{Density}

The average of panel density was presented in Figure 3. This study found that the panel density values were below the target density $\left(0.75 \mathrm{~g} / \mathrm{cm}^{3}\right)$. This may be as the result of spring back during hot pressing period. 


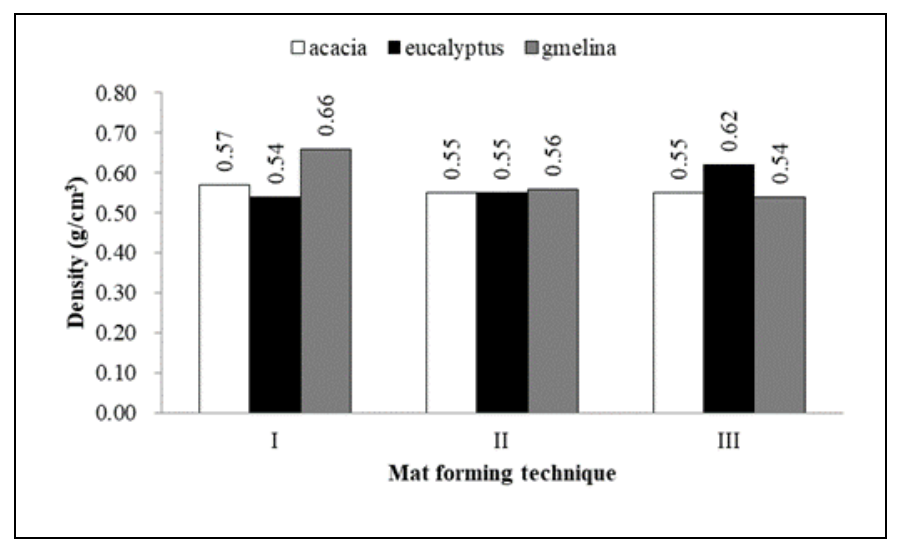

Figure 3 Histogram of density panels.

\subsection{Moisture content determination}

Then calculation result of strand panels showed the value ranged between of 12.34 to $17.90 \%$ as presented in Figure 4.

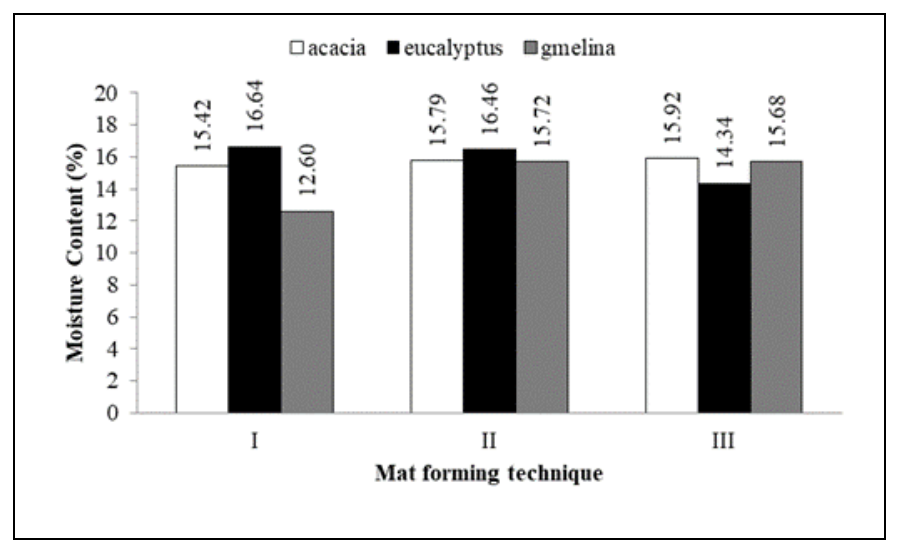

Figure 4 The histogram of moisture content panels.

Generally, the obtained results of strand moisture panels did not meet the JIS A 59082003 that required moisture between 5 to $13 \%$. This is because the strand panels were not dense enough as the impact of a low adhesive rate in the panels (5 part of total panel weight) that caused the strands were easily absorbed air moisture during conditioning period.

The mat forming technique did not have impact to the moisture of strand panels. The high strand panel moisture content may be due to a gap between strands that allowed the wood strands to absorb ambient air moisture. The entered panel moisture is differentiated by intruded water in the panels that filled the empty cavities inside part of the panels and the moisture that enters in the wood particles that forms the panels [10].

\subsection{The thickness swelling}

The thickness swelling was obtained after 2 and 24 hours soaking the panels as showed in Figure 5. The highest thickness swelling of the strand panels was in eucalyptus wood. 


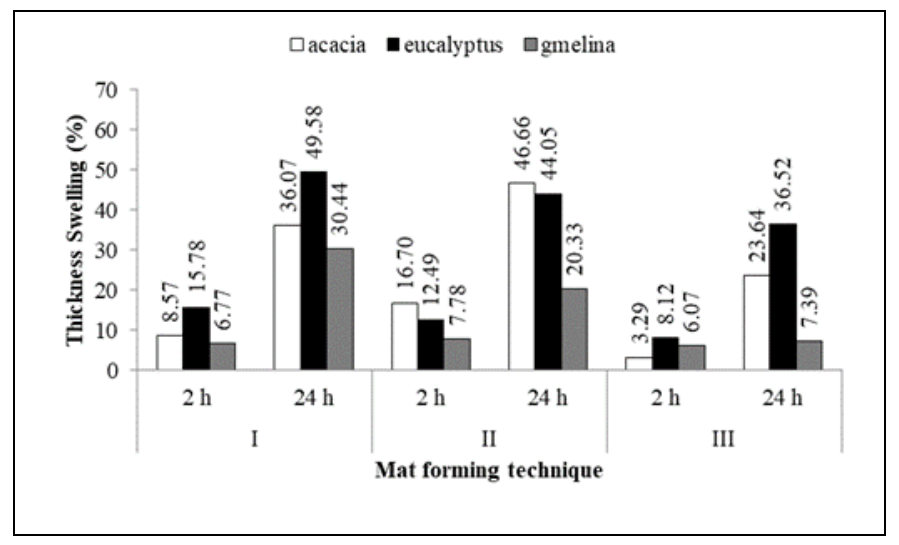

Figure 5 The histogram of thickness swelling panels.

The highest value of thickness swelling in eucalyptus wood was affected by wood density of eucalyptus. In the average, eucalyptus wood density was 0.61 which is higher than that of acacia (0.57) and gmelina (0.57). The eucalyptus wood density has caused its compression ratio of this wood was lower (1.23) than that of acacia (1.32), gmelina (1.32) and also lower than that of suggested by Maloney in [11] for about 1.30 to generate high quality panels.

High thickness swelling values were also caused by the use of a one percent of paraffin wax as the only protector source from water. Bowyer et al. cited in [3] suggested that to get the protection from water and to be water resistant, the amount of paraffin wax added in the strand panels should be $2 \%$

\subsection{Water absorption}

The result of water absorption percentage during 2 and 24 hours soaking period of the strand panels is presented in Figure 6. The water absorption of strand panel was the lowest using the orientation technique III compared to the other techniques. This is because the distribution of strands were fairer in the technique III as the result of the gravitation force when the strands were dropped that avoid the gap for being formed due to plywood barrier, and, of course, faster than technique I which was arranged manually.

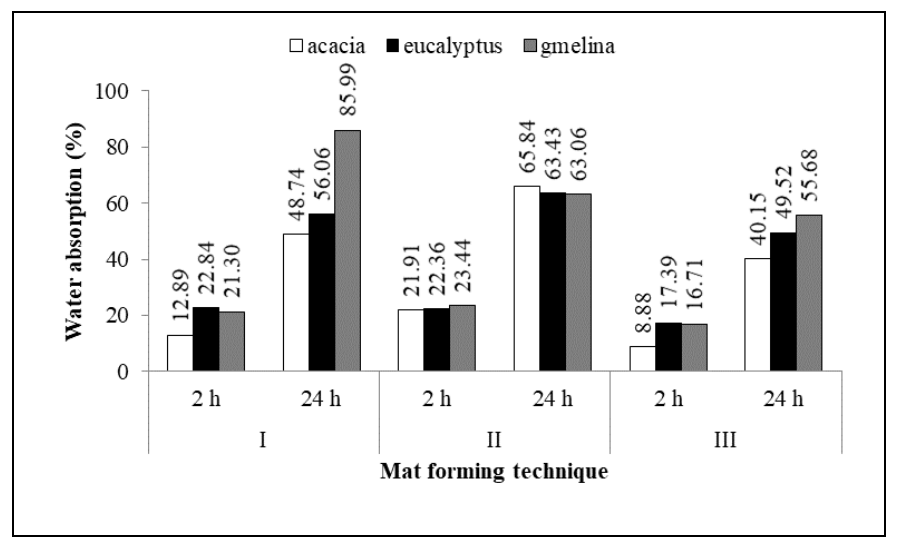

Figure 6 The histogram of water absorption value panels. 


\subsection{Internal bonding}

The values of internal bonding were presented in Figure 7.

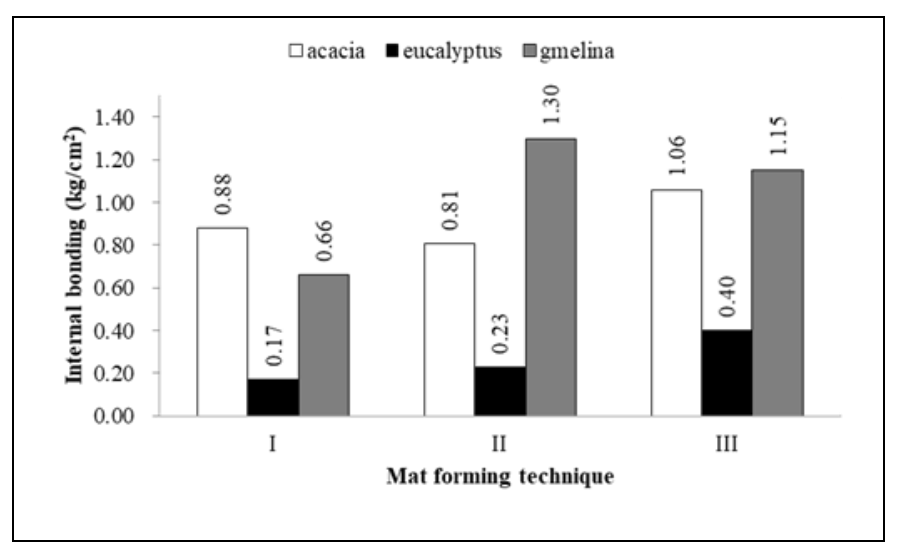

Figure 7 The histogram of internal bonding strand panels.

This study showed that the value of internal bonding did not meet JIS A 5908 standard 2003, which required $3.10 \mathrm{~kg} / \mathrm{cm}^{2}$ [1]. The uneven distribution of adhesives due to the powdered form and the low rate of adhesive used, caused the low value of internal bonding. The average damage was occurred in the middle part of the strand panels. This indicates that the bonding between the strand mats and the adhesive powder may be not strong enough, hence, the bonding between the strand mats is not optimum yet. The PF adhesive powder that has been attached to the wooden strands during blending period will form spots/dots when they are exposed to the heat and results in less strong bonding compared to the liquid adhesive that can penetrate and form a better mechanical anchor [12] as well as mechanical interlock [13].

The effect of mat formation technique, as has been seen in Figure 7, showed a no indication to be able to generate high value of internal bonding. Thus, it can be concluded that internal bonding is not affected by strand mat forming techniques.

\subsection{Modulus of rupture}

The value of modulus of rupture (MOR) is presented in Figure 8 and 9. The MOR of strand panels was analyzed in two different positions: parallel along the length and the width directions (perpendicular to the length of panels).

The results displayed that the MOR values parallel along the panels in acacia woods using the forming panel technique III is exceeded the JIS standard. The JIS standard required the minimum MOR amounted to $245 \mathrm{~kg} / \mathrm{cm}^{2}$ for parallel position along the panel length [1].

The mat forming technique I did not meet the JIS standard because the manual arrangement of strands following bricks construction will weaken the panels especially with the addition loading at the ends of the strand. In addition, a low level of adhesive used makes the bonds between strands less compact. 


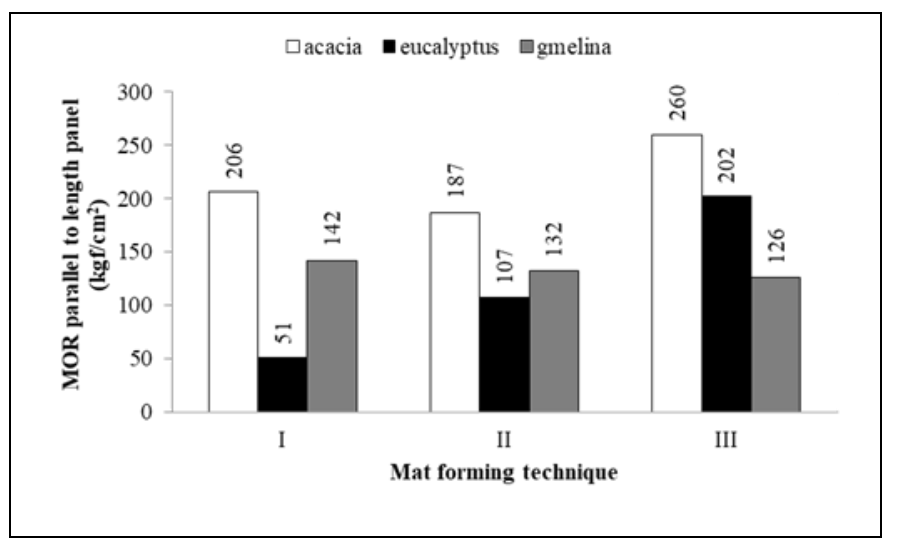

Figure 8 The histogram of MOR parallel to the length panels.

The values of MOR strand mats forming technique II for parallel length also did not meet JIS standards because this technique created cavity / gap among strands on the panels as an effect of the plywood that is used as the strands direction can create a barrier that makes the bonds between strands is less compact and resulting in low values. Koch [4] suggested that the value of MOR is influenced by several important factors, such as the orientation of strands, the density and the type of wood, the quality of the strand, the adhesive content, the moisture content of the panels, the procedure of pressing, and the panel density.

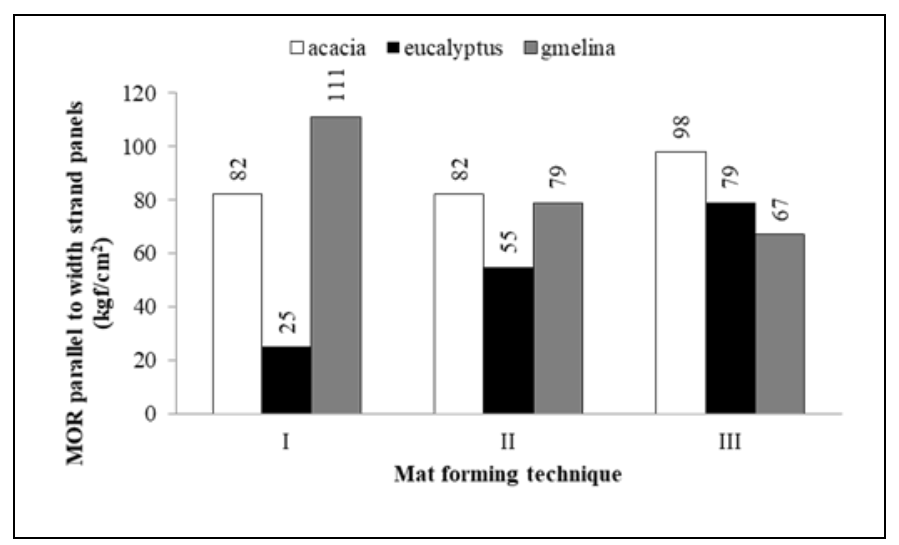

Figure 9 The histogram of MOR values parallel to width panels

The test results of MOR parallel to width strand panels were in the range between 25 and 111 $\mathrm{kg} / \mathrm{cm}^{2}$ as presented in Figure 9. The MOR parallel to width strand panels or perpendicular to length strand panel values of acacia and eucalyptus wood tend to increase in techniques I, II, and III; by contrast, gmelina exhibits the opposite trends. This indicated that the test affects the results. If the test is conducted on the strand gaps, the results can be small and vice versa if the measurements have been done on the strands body. To conclude, the strand formation techniques can only work to orientate strands while the value of the MOR is depended on the sample position when the test is carried out, whether the load is on the tip or body of the strands.

\subsection{Modulus of elasticity}

Similar to the MOR, the modulus of elasticity (MOE) of the strand panels is tested in two positions, parallel to the length and to the width direction (perpendicular to the length of the 
strand panels). The results showed that the MOE parallel to the length direction as presented in Figure 10 did not meet JIS A 59082003 standard, which required a minimum score of 40,800 $\mathrm{kg} / \mathrm{cm}^{2}$. However, the mat formation technique III generated higher results than that from the mat formation technique I and II. This suggests that the mat formation technique III produces the expected strands that do not create gaps/cavities as technique II does. Related to damage due to loading, the mat formation technique I will generate a systematic damage in the strands gap/connection as in the brick construction. Thus, the results of this study strengthen the previous theory that the orientation and position of the strands will affect the MOE of the resulting bending.

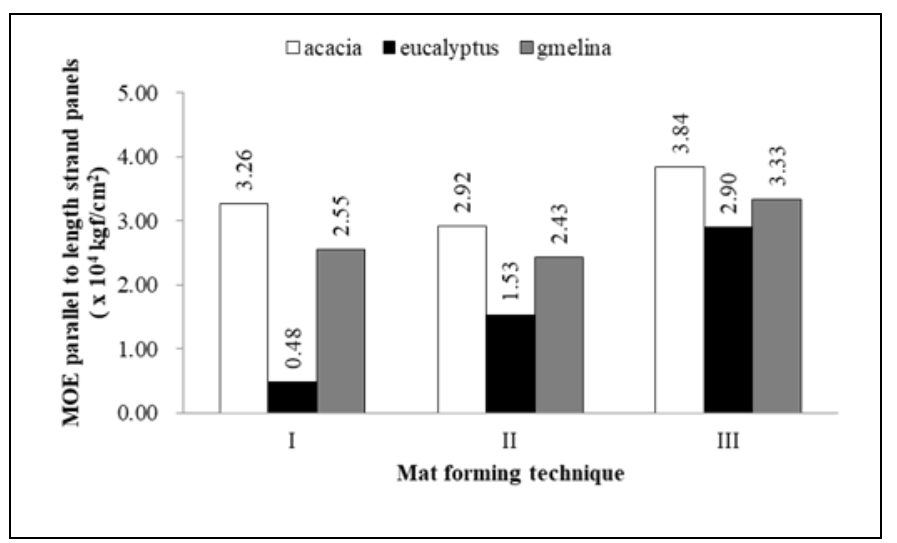

Figure 10 The histogram of MOE parallel to length panels.

Similar to parallel to the length strand panels condition, the test of MOE on the strands width results (perpendicular to the long direction) were presented in Figure 11 and it showed that the results did not meet JIS A 59082003 standard which requires a minimum value of $1.33 \times 104$ $\mathrm{kg} / \mathrm{cm}^{2}$. The trend of the results is also similar with the test of MOE parallel to the strands length; the MOE using the technique III generated relatively high results compared to the techniques I and II. This is because technique III can eliminate the occurrence of gaps/cavities in the strand composers.

Figure 11 presents that the eucalyptus board has a much lower MOE than that from acacia and gmelina wood. This finding is in agreement with Maloney cited in [11] that suggests wooden particle panels with a high wood density will have a low MOE. It has been proven that with a mean wood density of $0.61 \mathrm{~g} / \mathrm{cm}^{3}$, eucalyptus has a lower MOE compared to acacia and gmelina that have a mean of wood density of $0.57 \mathrm{~g} / \mathrm{cm}^{3}$. 


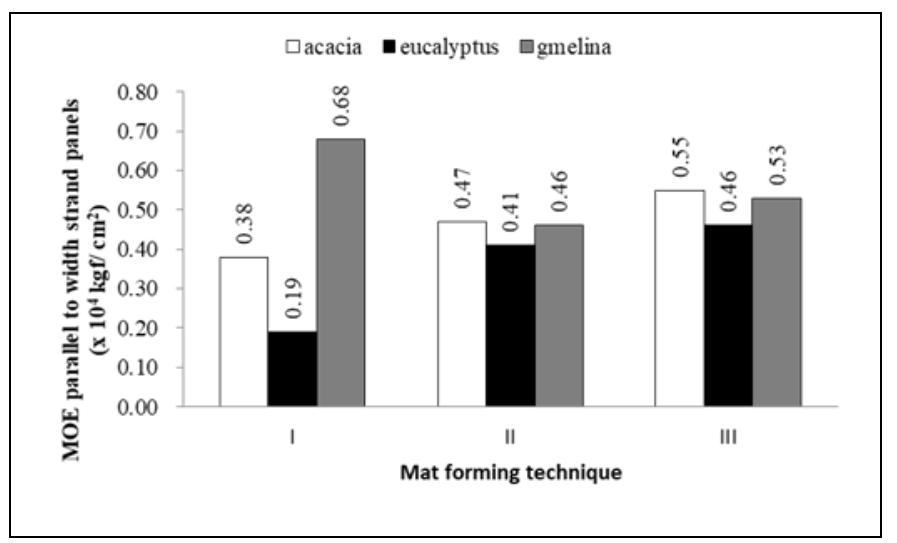

Figure 11 The histogram of MOE parallel to width panels.

\subsection{The best strand panels model}

The best strand panel was determined based on the best result of the mechanical and physical testing/meet the JIS A 5908 2003. The quality of the strand panels was arranged based on the analysis results with the highest testing value as the best strand panels.

Table 1 The rank of acacia-made strand panels analysis based on the three mat strands forming techniques

\begin{tabular}{lccc}
\hline \multirow{2}{*}{$\begin{array}{c}\text { The analysis of physical and mechanical } \\
\text { characteristics }\end{array}$} & \multicolumn{3}{c}{ The analysis rank } \\
\cline { 2 - 4 } & I & II & III \\
\cline { 2 - 4 } $\begin{array}{l}\text { Physical characteristics } \\
\text { Density }\end{array}$ & 3 & 1 & 2 \\
Moisture content & 3 & 2 & 1 \\
Thickness swelling & 2 & 1 & 3 \\
- 2 hours & 2 & 1 & 3 \\
- 24 hours & & & \\
Moisture absorption & 2 & 1 & 3 \\
- 2 hours & 2 & 1 & 3 \\
- 24 hours & & & \\
Mechanical characteristics & 2 & 1 & 3 \\
Internal bonding & 2 & 1 & 3 \\
MOR parallel to the length & 1 & 2 & 3 \\
MOR parallel to the width & 2 & 1 & 3 \\
MOE parallel to the length & 1 & 2 & 3 \\
$\quad$ MOE parallel to the width & $\mathbf{2 2}$ & $\mathbf{1 4}$ & $\mathbf{3 0}$ \\
\hline Total analysis score & &
\end{tabular}

Note : $3=$ good, $2=$ fair, $1=$ poor

Table 1 displayed that acacia-made strand panels that was made using the mat forming technique III would generate the best physical and mechanical characters compared to the ones that was made using the mat forming technique I and II, with the total value 30, although it does not meet with JIS A 59082003 standard yet.

Table 2 showed that the eucalyptus-made by the mat strand forming technique III generates the best physical and mechanical properties compared to those made with techniques I and II, with a sum of score 33, although it does not meet the JIS A 5908 (2003) standard yet. 
Table 2 The rank of eucalyptus-made strand panels analysis based on the three mat strands forming techniques

\begin{tabular}{lccc}
\hline \multirow{2}{*}{$\begin{array}{c}\text { The analysis of physical and mechanical } \\
\text { characteristics }\end{array}$} & \multicolumn{3}{c}{ The analysis rank } \\
\cline { 2 - 4 } & I & II & III \\
\cline { 2 - 4 } $\begin{array}{l}\text { Physical characteristics } \\
\text { Density }\end{array}$ & 1 & 2 & 3 \\
$\quad$ Moisture content & 1 & 2 & 3 \\
Thickness swelling & & & \\
- 2 hours & 1 & 2 & 3 \\
- 24 hours & 1 & 2 & 3 \\
Moisture absorption & & & \\
- 2 hours & 1 & 2 & 3 \\
- 24 hours & 2 & 1 & 3 \\
Mechanical characteristics & & & \\
Internal bonding & 1 & 2 & 3 \\
MOR parallel to the length & 1 & 2 & 3 \\
MOR parallel to the width & 1 & 2 & 3 \\
MOE parallel to the length & 1 & 2 & 3 \\
MOE parallel to the width & 1 & 2 & 3 \\
\hline Total analysis score & $\mathbf{1 3}$ & $\mathbf{2 1}$ & $\mathbf{3 3}$ \\
\hline
\end{tabular}

Note : 3= good, $2=$ fair, $1=$ poor

Table 3 The rank of gmelina-made strand panels analysis based on the three mat strands forming techniques

\begin{tabular}{lccc}
\hline \multirow{2}{*}{$\begin{array}{c}\text { The analysis of physical and mechanical } \\
\text { characteristics }\end{array}$} & \multicolumn{3}{c}{ The analysis rank } \\
\cline { 2 - 4 } & I & II & III \\
\cline { 2 - 4 } $\begin{array}{l}\text { Physical characteristics } \\
\text { Density }\end{array}$ & 3 & 2 & 1 \\
Moisture content & 3 & 1 & 2 \\
Thickness swelling & 2 & 1 & 3 \\
- 2 hours & 1 & 2 & 3 \\
- 24 hours & & & \\
Moisture absorption & 2 & 1 & 3 \\
2 hours & 1 & 2 & 3 \\
- 24 hours & & & \\
Mechanical characteristics & 1 & 3 & 2 \\
Internal bonding & 3 & 2 & 1 \\
MOR parallel to the length & 3 & 2 & 1 \\
MOR parallel to the width & 2 & 1 & 3 \\
MOE parallel to the length & 3 & 1 & 2 \\
MOE parallel to the width & $\mathbf{2 4}$ & $\mathbf{1 8}$ & $\mathbf{2 4}$ \\
\hline Total analysis score & &
\end{tabular}

Note : $3=$ good, $2=$ fair, $1=$ poor

Table 3 suggested that the gmelina-wood strand panels that are made by the mat strand forming technique I and III have an improved physical and mechanical properties compared to those that is made by technique II, with a score of 24, even though they have yet to meet JIS A 59082003 standard. 


\section{Conclusion}

The mat strand forming techniques III using the strand direction-oriented tool with plywood and wire that is a modification of an invented tool by Nishimura et al. [2] is the best and the most efficient technique to produce all types of wood strand panels. Nevertheless, the strand panels produced generally do not meet JIS A 59082003 standards due to insufficient rate of adhesives and further research is needed to analyze the optimum moisture content for fairly distributing and optimally bonding of PF adhesive powder.

\section{REFERENCES}

[1] Japanese Standard Association, "Japanese Industrial Standard for particle board JIS A 5908," Japanese Standard Association, Jepang, 2003.

[2] T. Nishimura, J. Amin, and M. P. Ansell, "Image analysis and bending properties of model OSB panels as a function of strand distribution, shape and size," Wood Science and Technology, vol. 38, no. 4, pp. 297-309, 2004.

[3] J. L. Bowyer, R. Shmulsky, and J. G. Haygreen, Forest Products and Wood Science an Introduction, Iowa (USA): The Iowa State University Press AMES, 2003.

[4] P. Koch, Utilization of Hardwoods Growing on Southern Pine Sites; Agricultural Handbook SFES-AH-605, Asheville, North Carolina (USA): USDA-Forest Service, Southern Forest Experiment Station, 1985.

[5] J. Puspariani, "Sifat fisis dan mekanis oriented strand board yang terbuat dari kayu pinus (Pinus merkusii Jungh et de Vries), karet (Hevea brasiliensis Muell.Arg) dan akasia (Acacia mangium Willd)," Undergraduate Thesis, Department of Forest Product Technology, Faculty of Forestry, Bogor Agricultural University, Bogor, 1996.

[6] I. Ridwan, "Sifat fisis dan mekanis oriented strand board kayu terap (Artocarpus elasticus Reinw.) dan kayu weru (Albizia procera Benth.)," Undergraduate Thesis, Department of Forest Product Technology, Faculty of Forestry, Bogor Agricultural University, Bogor, 1997.

[7] Sutrisno, "Pengaruh nisbah tekan terhadap sifat papan untai kayu sengon dan tusam," Master Thesis, Graduate School, Bogor Agricultural University, Bogor, 1999.

[8] A. Y. M. Tasdiq, "Pengaruh perbandingan dimensi panjang dan tebal strands terhadap sifat fisis dan mekanis oriented strand board dari kayu gmelina (Gmelina arborea Roxb.)," Undergraduate Thesis, Department of Forest Product Technology, Faculty of Forestry, Bogor Agricultural University, Bogor, 2000.

[9] Yusfiandrita, "Pengaruh pengukusan strands terhadap sifat fisis dan mekanis oriented strand board dari jenis kayu terap (Artocarpus elasticus Reinw.) dan kayu weru (Albizia procera Benth.)," Undergraduate Thesis, Department of Forest Product Technology, Faculty of Forestry, Bogor Agricultural University, Bogor, 1988.

[10] M. Y. Massijaya, and S. S. Kusumah, "Analisis kelayakan teknis papan komposit dari limbah kayu dan karton gelombang untuk bahan bangunan dan meubel," Jurnal Teknologi Hasil Hutan, vol. 18, no. 2, pp. 62-69, 2005.

[11] T. M. Maloney, Modern particleboard and dry-process fiberboard manufacturing (updated edition), San Francisco (USA): Miller Freeman, 1993.

[12] A. N. Gent, and G. R. Hamed, "Fundamentals of Adhesion," Handbook of Adhesives, I. Skeist, ed., pp. 39-73, Boston, MA: Springer US, 1990.

[13] L. Gollob, and J. D. Wellons, "Wood Adhesion," Handbook of Adhesives, I. Skeist, ed., pp. 598-610, Boston, MA: Springer US, 1990. 